\title{
CLIMATE CHANGE IMPACTS ON SEA SURFACE TEMPERATURE IN THE EASTERN MEDITERRANEAN, LEVANTINE BASIN
}

\author{
Y. Samuel-Rhoads ${ }^{1}$, G. Zodiatis ${ }^{1}$, D. Hayes ${ }^{1 *}$, G. Konnaris ${ }^{1}$ and G. Georgiou ${ }^{1}$ \\ 1 Oceanography Centre University of Cyprus - dhayes@ucy.ac.cy
}

\begin{abstract}
Increases in SSTs have been recorded to occur in the Mediterranean at about twice the rate as that of the global oceans. Here we analyze and compare satellite remote sensing SST data with in-situ data from 1996 to 2012 in the Levantine. Further, SST profiles from oceanographic cruises and gliders were processed to study the variability at the surface layer $(0-10 \mathrm{~m})$. These data were collected during several CYBO research cruises that the Oceanography Centre has conducted, as well as during missions of the gliders owned and operated by the OC. We show that the Levantine has undergone SST increases, and that satellite and in-situ SST data are correlated. The driving mechanisms of these changes need to be investigated, in order to understand the future trends and impacts of climate change in the region.
\end{abstract}

Keywords: Temperature, Remote sensing, Surface waters, Levantine Basin

Several studies have reported regional temperature increases in the Mediterranean Sea for each of its two basins [1-5]. Changes occurring in the eastern and western basins are frequently out of phase as a consequence of different processes that affect the climate of the two [6-7]. Overall, SSTs across the Mediterranean as a whole have been rising about twice as much as those of the global oceans [8-9]. The objective of this work is to investigate the increase in SST due to climatic changes in the Eastern Mediterranean Levantine basin from 1996 until 2012, with the use of satellite remote sensing data as well as with in-situ data.

Analyses of annual mean satellite sea surface temperature (SST) data indicate that over the last years a general warming has occurred over the Levantine Basin, and occurred at an average rate of approximately $0.065^{\circ} \mathrm{C}$ per year. This increase in average SSTs is also seen in the seasonal averages, especially during the summer. Spatial variability in the decadal warming is depicted in the satellite SST anomalies, with positive anomalies dominating most of the Levantine during the years 1999, 2001, 2002, 2003, and 2008. The highest sea surface temperatures appear in 1999, 2003, and 2008. An area southeastern of Cyprus is seen during some years to be warming up much more strongly than the rest of the Levantine Basin. Empirical Orthogonal Function (EOF) analysis was performed on the annual and seasonal satellite SST data to examine their spatial and temporal patterns of variability. The spatial eigenfunctions of mode 1 show that the seasonal and annual SSTs across the entire Levantine share high positive eigenfunctions and thus varied in a spatially coherent manner over time. Therefore, the SST variability is characterized by a broad, basin-wide warming (mode 1). The seasonal principal component (PC) of the same mode (PC1), which depicts the time variation of the first mode, varied over the years supporting the fact that the Levantine is experiencing a strong seasonal cycle. The PC1 of the annual data supports the fact that higher than average SSTs were observed across the Levantine during the later part of the time period. An asymmetry in the N-to-S direction is depicted in the spatial eigenfunctions of mode 2. Areas in the northern Levantine are out of phase from areas in the southern parts of the basin, creating a dipole pattern of heating and cooling at interannual and interseasonal time scales. Analyses of annual and summer insitu SST data reveal similar increases in temperatures to the ones recorded by satellites in the region. The average rate of increase of SSTs is $0.53^{\circ} \mathrm{C}$, which is approximately three times higher than the recorded $0.18^{\circ} \mathrm{C}$ rate of increase of global SSTs [10]. During the year 2010, the highest temperatures were recorded up to date, which were much higher than the recorded ones from summer of 2003 (mean values for the summer of 2010 for $\mathrm{T}=29.57^{\circ} \mathrm{C}$ ). Analyses of monthly in-situ SST data collected during glider expeditions from 2009 until 2012, and calculated for the top 10 meters of the water column, reveal the monthly variability in temperatures in the Levantine basin. However, the time series in some cases does not represent well the entire region of interest, as the gliders may have been in an area with a local effect, which is then affecting the regional averages. Further examination, processing and analysis of these data is needed.

The present study has shown that an increase in the Levantine Basin sea surface temperatures (SSTs) has taken place from 1996 to 2012. The SST variability is characterized by a broad, basin-wide warming (mode 1) occurring at both seasonal and interannual time scales, and a weaker dipole pattern that fluctuates at similar time scales (mode 2). Further, satellite SST data are correlated with in-situ CTD SST data, especially during the summer months. The warming in the Levantine, which is revealed by the satellite SST data, as well as by the recorded increases in in-situ SSTs, occurred at both seasonal and interannual time scales. The fact that in 2010 the highest temperatures have been recorded so far, which were even higher than the record values of 2003, indicates that the increasing trend is expected to continue. The driving mechanisms of these changes need to be investigated, as they may be driven by changes in annual latent heat losses and by the variability in regional wind speeds.

\section{References}

1 - Astraldi, M., Balopoulos, S., Candela, J., Font, J., Gacic, M., Gasparini, G. P., Manca, B., Theocharis, A., and Tintore, J., 1999. The role of straits and channels in understanding the characteristics of Mediterranean circulation. Prog. Oceanogr., 44: 65-108.

2 - Bethoux, J.P. and Gentili, B., 1999. Functioning of the Mediterranean Sea: past and present changes related to freshwater input and climate changes. J. Mar. Syst., 20: 33-47.

3 - Demirov, E. and Pinardi, N., 2002. Simulation of the Mediterranean Sea circulation from 1979 to 1993: Part I. The interannual variability. J. Mar. Syst., 33-34: 23-50.

4 - Sabatés, A., Martín, P., Lloret, J. and Raya, V., 2006. Sea warming and fish distribution: the case of the small pelagic fish, Sardinella aurita, in the western Mediterranean. Global Change Biology, 12: 2209-2219.

5 - Salat, J. and Pascual, J., 2002. The oceanographic and meteorological station at l'Estartit (NW Mediterranean). Tracking long-term hydrological change in the Mediterranean Sea. CIESM Workshop Series, 16: 29-32.

6 - Artale, V., Calmanit, S., Malanotte-Rizzoli, P., Pisacane, G., Rupolo, V. and Tsimplis, M, 2006. The Atlantic and Mediterranean Sea as connected systems. In: Lionello, P., Malanotte-Rizzoli, P. and Boscolo, R. (eds.), Mediterranean Climate Variability, Elsevier, The Netherlands, pp 283-323.

7 - Korres, G., Pinardi, N. and Lascaratos, A., 2000. The ocean response to low frequency interannual atmospheric variability in the Mediterranean Sea, Part I: Sensitivity experiments and energy analysis. J. of Climate, 13: 705731.

8 - Samuel-Rhoads, Y., Iona, S., Zodiatis, G., Hayes, D., Gertman, I. and Georgiou, G., 2009. Sea surface temperature and salinity variability in the Levantine Basin during the last decade, 1996 to 2006. EGU General Assembly 2009, vol. 11.

9 - Zodiatis, G., Samuel-Rhoads, Y., Solovyov, D., Hayes, D., Konnaris, G. and Papazachariou, D., 2011. Monitoring the Levantine basin through the use of multiple satellite remote sensing products. EGU General Assembly 2011, vol. 13 .

10 - Good, S.A., Corlett, G.K., Remedios, J.J., Noyes, E.J. and LlewellynJones, D.T., 2007. The global trend in sea surface temperature from 20 years of Advanced Very High Resolution Radiometer Data. J. Clim., 20: 12551264. 